\title{
Use of dietary supplements by breast cancer patients undergoing conventional cancer treatment
}

\author{
Lai Yi Eliza Wong' \\ Ping Chung Leung ${ }^{2}$ \\ Jin-Ling Tang ${ }^{3}$ \\ Stewart W Mercer ${ }^{4}$ \\ 'Department of Community and \\ Family Medicine, ${ }^{2}$ Institute of Chinese \\ Medicine, ${ }^{3}$ Hong Kong Branch of The \\ Chinese Cochrane Centre, School of \\ Public Health, The Chinese University \\ of Hong Kong, New Territories, \\ Hong Kong; ${ }^{4}$ Centre of Population \\ Health Services, College of Medical, \\ Veterinary \& Life Sciences, General \\ Practice and Primary Care, University \\ of Glasgow, Glasgow, UK
}

This article was published in the following Dove Press journal:

Patient Preference and Adherence

17 November 2010

Number of times this article has been viewed
Background: Many breast cancer patients use some form of dietary supplement (DS) to complement their conventional cancer treatment, in the hope that they might lessen the side effects of treatment, improve quality of life, give a greater sense of control, and reduce stress. This pilot study assessed the level of DS usage by breast cancer patients undergoing conventional cancer treatment, and their concerns about the use of DS.

Method: A cross-sectional descriptive survey in three breast cancer centers in Hong Kong using face-to-face interviewing was performed.

Results: Of 82 female Chinese breast cancer patients who completed the survey, $99 \%$ reported that they had been using DS since their cancer was diagnosed. The most frequently used DS were Chinese herbal medicines, and patients spent about US\$258 on DS every month. The reason given for using DS was to enhance their recovery from cancer, but at the same time the patients had safety concerns. However, most patients did not feel able to discuss these concerns with health professionals.

Conclusion: The majority of the patients had some safety concerns, and said that they would welcome detailed and reliable information on DS. The lack of reliable information on the potential risks and benefits of using such supplements as an adjuvant to conventional treatment and the reluctance of patients to discuss their use of DS with health professionals is a major area of concern that warrants further attention.

Keywords: breast cancer, dietary supplement, prevalence, concern, expense

\section{Introduction}

Breast cancer is the most common malignancy diagnosed in women across the world today. ${ }^{1}$ Treatment options for breast cancer patients include surgery, radiotherapy, chemotherapy, and hormone replacement therapy. Such treatments are aimed at limiting the spread of cancerous cells in the body and containing the damage they inflict. Although advanced cancer treatments have marginally increased the survival rate of patients with breast cancer during the past decade, they often produce unpleasant complications. ${ }^{2}$ As a result, the experience of suffering from cancer is often a dreadful ordeal for patients, even for those who survive the disease. Besides coming to terms with the diagnosis of a life-threatening disease, many cancer patients are exposed to the unpleasant side effects of the treatment they receive, including fatigue, anxiety, menopausal symptoms, nausea, lymphedema, and dermatitis. These complications are side effects of life-saving therapies, can impair patients' vitality and lower their quality of life, and are often very difficult to adjust to psychologically. ${ }^{3}$ Many breast cancer patients therefore use some form of complementary and alternative medicine (CAM) in addition to conventional 
cancer treatments, in the hope that they might lessen the side effects of treatment, improve quality of life, give them a greater sense of control, and reduce stress. ${ }^{4-8}$ Surveys in the UK, Australia, and the US have shown that $10 \%-49 \%$ of the general population have used at least one form of CAM. ${ }^{9,10}$ CAM use appears to be even higher in Singapore, where a recent survey found that $76 \%$ of the population had used at least one form of CAM over a 12-month period. ${ }^{11} \mathrm{~A}$ number of surveys have found that the use of CAM as an adjuvant to cancer treatment is more frequent among breast cancer patients $(63 \%-87 \%)$ than among other cancer patients. ${ }^{4,12-14}$ In light of the fashionable use of CAM in the public arena, the American Hospital Association undertook a recent survey which showed that about $72 \%$ of hospitals in metropolitan regions are offering CAM. ${ }^{15}$

Recent studies have found that more than $80 \%$ of cancer patients reported having used CAM, and that $75 \%$ of these patients did not tell their doctors that they were doing so. ${ }^{16,17}$ Dietary supplements (DS), such as herbs and vitamins, are the most popular choices of CAM among cancer patients. ${ }^{4,18-20}$ According to the US Food and Drug Administration (FDA), a dietary supplement is defined as follows:

A product taken by mouth that contains a "dietary ingredient" intended to supplement the diet. The "dietary ingredients" in these products may include: vitamins, minerals, herbs or other botanicals, amino acids, and substances such as enzymes, organ tissues, glandular, and metabolites ... also extracts or concentrates, and may be found in many forms such as tablets, capsules, soft gels, gel caps, liquids, or powders. ${ }^{21}$

Under the Dietary Supplement Health and Education Act (DSHEA) of 1994, dietary supplements are regulated in the US as foods, not drugs. Unlike pharmaceutical companies, DS manufacturers are not required to prove the safety or effectiveness of their products, and the FDA can take action only after a DS has been proven to be harmful. ${ }^{22}$ Many countries, including Hong Kong, take the reference of the DSHEA for regulating DS. Therefore, some patients may consider a DS as a type of food which need not be taken into account in a detailed drug history. This may be a dangerous assumption. A pharmacologic study has shown that a high dose of vitamin $\mathrm{C}$, an antioxidant, can interfere with radiotherapy, while some herbs may increase the risk of bleeding during surgery. ${ }^{23}$ However, very few breast cancer patients who use DS seem to be aware that there may be risks associated with use of such preparations. Because the use of DS is so widespread among breast cancer patients, there is an urgent need to study how patients use such supplements and how they regard them, so that communication between health professionals and patient educators and patients can be improved, and patients can be properly informed of the benefits and risks involved in the use of DS. Thus, this pilot study was undertaken to assess the level of usage of DS by breast cancer patients undergoing conventional cancer treatment and their concerns about the use of DS.

To obtain this information, this survey investigated: characteristics of DS users; patterns of utilization of DS, including the commencement of DS; types of DS used and associated costs; reasons why subjects used them; whether subjects disclosed their use of DS to clinicians, and their reasons for disclosure or nondisclosure; and whether subjects had concerns about their use of DS, including adverse events, and if so, the nature of these concerns.

\section{Methods}

\section{Study design and population}

The study took the form of a cross-sectional descriptive survey. A convenience sampling of 100 breast cancer women from cancer centers of a university-affiliated hospital, a government hospital, and a private clinic in Hong Kong, would be invited for the study after written informed consent was obtained during their routine oncology follow-up in 2002. Strict inclusion criteria were adopted. The participants had to be female Cantonese speakers without cognitive or physical impairments, at least 30 years old, diagnosed with Stage I-III breast cancer according to the International Union Against Cancer TNM Classification of Malignant Tumors and the American Joint Committee on Cancer stage grouping, ${ }^{24}$ who had cancer in only one breast and no cancer metastases, and who had completed an anticancer treatment (eg, surgery, chemotherapy, radiotherapy) in the previous three years, and were not receiving any concurrent medical treatment.

\section{Questionnaire}

Individual face-to-face interviews using a semistructured questionnaire were designed to assess the response to DS use among breast cancer patients. The interview questionnaire was developed from an indepth literature review and expert panel review (two physicians and one nurse). The questionnaire was also tested for understanding in 10 patients. The questionnaire sought demographic information, patterns of DS use, including commencement of using DS, type, frequency, and cost of using DS in the past three months, reasons for using a DS, willingness to disclose DS use to 
oncologists or nurses, and concerns about adverse events from using DS. Demographics, including age, gender, education, occupation, religion, marital status, country of birth, area of residence, and duration of living in Hong Kong were obtained to supplement existing information on the respondents' health status. The interviews lasted approximately 20 minutes and were conducted by trained interviewers.

\section{Data collection}

Informed written consent was obtained from the subjects during a routine oncology follow-up, and face-to-face interviews were then arranged with each subject. Subjects were telephoned the day before the interview and requested to write down any type of DS they had used in the previous three months, including Western supplements, herbal tea (ingredients), herbal soup (ingredients), and Chinese proprietary medicinal supplements, and to state how much they had spent on such supplements. A period of only three months was used as the reference in order to minimize recall bias. During the interview, the subjects were first asked whether they had ever used DS during conventional cancer treatment, and if so, which types of DS they had been using in the previous three months and what their ingredients were, how often they used them, and how much (in Hong Kong dollars) they spent each month on them. They were also asked why they used DS and whether any adverse events had occurred while they were taking them. Finally, they were asked how they had learned about DS, and whether they disclosed their use of DS to their oncologist or nurse.

\section{Statistical analyses}

All data management and analyses were performed using SPSS (version13.0; SPSS Inc, Chicago, IL) Types, prevalence, and patients' reasons for DS use, attitude towards disclosing DS use to oncologists or nurses, and concerns about using DS, were described in percentage terms. The descriptive statistics were generated first, and the associations between independent and dependent variables were then evaluated. Monthly expenditure on each type of supplement was calculated. In extrapolating expenditure on DS, the survey data were based on monthly expenditure by the individual patient, not her household. The Chi-square test or Fisher's exact test was applied to estimate the association between the demographic and clinical characteristics of patients and their DS utilization. The significance level for all analyses was set at alpha 0.05 , and all tests were two-sided.

\section{Ethical considerations}

The study was approved by the institutional review board of the university involved in the study. All potential participants were informed of the details and significance of the study and written consent was obtained before the interview. All participants were given the opportunity to withdraw from the study at any point and were assured that interviewers were independent of the services and that the interviews would be confidential.

\section{Results}

\section{Response rate and characteristics of sample}

Of the 100 breast cancer patients invited to take part in the survey, 82 completed the face-to-face interviews between June and October 2002, ie, a response rate of $82 \%$. The 18 breast cancer patients who declined to participate in the study said either that they did not have time or that they were not willing to discuss any issue related to cancer. Characteristics of the 82 breast cancer subjects are shown in Table 1. The mean age of the participants was $45.8 \pm 6.9$ years and the mean time from the initial diagnosis of cancer to the survey was $56.1 \pm 28.3$ weeks. Most of the subjects had either secondary or higher education (56\%), were married (84\%), were housewives (66\%), and held some sort of religious belief $(60 \%)$. Over half were born in Hong Kong (59\%), and had lived in Hong Kong for $35.5 \pm 15.2$ years.

\section{Characteristics of DS users}

The demographics of the 81 DS users and one nonuser were shown in Table 2. Eighty-one of the 82 breast cancer patients (99\%) reported that they had been using DS continually since their cancer was diagnosed.

\section{Pattern of DS use}

Eighty-one (99\%) of the 82 breast cancer patients who participated in the study reported that they had been using DS continually since their cancer was diagnosed. Twentyone patients $(26 \%)$ regularly took at least two types of DS. Table 3 shows that all of the 81 subjects taking DS used Chinese supplements. Fourteen of these subjects (17\%) also took Western supplements, and 12 (15\%) took supplements "extracted from other plants or animals". The most common Chinese supplement was herbal tea, taken by 53 subjects $(65 \%)$, herbal soup, taken by 48 subjects (59\%), and Chinese proprietary medicine, taken by 42 subjects $(52 \%)$. Table 4 shows that the most common herbal tea ingredient, used by $29 / 53$ subjects $(55 \%)$, was bai hua 
Table I Demographic and clinical characteristics of 82 breast cancer patients between June and October 2002 in Hong Kong

\begin{tabular}{|c|c|c|}
\hline & Mean (SD ) & Median (range) \\
\hline Age (years) & $45.8(6.9)$ & $45.0(30-63)$ \\
\hline Duration in & $35.5(15.2)$ & $40.0(1-59)$ \\
\hline \multicolumn{3}{|l|}{ Hong Kong (years) } \\
\hline \multirow{3}{*}{$\begin{array}{l}\text { Interval between } \\
\text { cancer diagnosis and } \\
\text { survey (weeks) }\end{array}$} & $56.1(28.3)$ & $52.0(8-140)$ \\
\hline & & \\
\hline & Category & Frequency (\%) \\
\hline Sex & Female & $82(100 \%)$ \\
\hline \multirow[t]{5}{*}{ Education } & $\leq$ Primary & $17(20.7 \%)$ \\
\hline & Form 3 & 19 (23.2\%) \\
\hline & $\begin{array}{l}\text { Form 5/vocational/ } \\
\text { technical/ }\end{array}$ & $28(34.1 \%)$ \\
\hline & matriculation level & $3(3.7 \%)$ \\
\hline & $\begin{array}{l}\text { university/diploma/ } \\
\text { postgraduate }\end{array}$ & $15(18.3 \%)$ \\
\hline \multirow[t]{5}{*}{ Occupation } & Health professional & $3(3.7 \%)$ \\
\hline & $\begin{array}{l}\text { Executive/nonhealth } \\
\text { professional }\end{array}$ & $5(6.1 \%)$ \\
\hline & White collar & $13(\mid 5.9 \%)$ \\
\hline & Blue collar & $7(8.5 \%)$ \\
\hline & $\begin{array}{l}\text { Housewife/ } \\
\text { unemployed }\end{array}$ & 54 (65.8\%) \\
\hline \multirow[t]{5}{*}{ Religion } & No religious belief & $33(40.2 \%)$ \\
\hline & Christianity & $17(20.7 \%)$ \\
\hline & Buddhism & $13(15.9 \%)$ \\
\hline & Ancestor & $2(2.4 \%)$ \\
\hline & Multireligion & $17(20.7 \%)$ \\
\hline \multirow[t]{4}{*}{ Marital status } & Single & $8(9.8 \%)$ \\
\hline & Married & 69 (84.1\%) \\
\hline & Divorced & $4(4.9 \%)$ \\
\hline & Widowed & $\mathrm{I}(\mathrm{l} .2 \%)$ \\
\hline \multirow[t]{3}{*}{ Location of birth } & Hong Kong & 48 (58.5\%) \\
\hline & Mainland China & 31 (37.8\%) \\
\hline & Other Asian countries & $3(3.7 \%)$ \\
\hline \multirow[t]{3}{*}{ Location of residence } & Hong Kong Island & $8(9.8 \%)$ \\
\hline & Kowloon & $24(29.3 \%)$ \\
\hline & New Territories & $50(61 \%)$ \\
\hline \multirow[t]{3}{*}{ Cancer status } & Stage I & $24(29.3 \%)$ \\
\hline & Stage II & 51 (62.2\%) \\
\hline & Stage III & $7(8.5 \%)$ \\
\hline \multirow[t]{4}{*}{ Cancer treatment } & Surgery & $82(100 \%)$ \\
\hline & Chemotherapy & $64(78 \%)$ \\
\hline & Radiotherapy & $6 \mathrm{I}(74.4 \%)$ \\
\hline & $\begin{array}{l}\text { Hormone replacement } \\
\text { therapy }\end{array}$ & $58(70.7 \%)$ \\
\hline
\end{tabular}

she cao (Oldenlandia diffusa). The most common herbal soup ingredient, used by $29 / 48$ subjects $(60 \%)$, was huai shan (Rhizome dioscoreae), and the most common Chinese proprietary medicine, used by $25 / 42$ subjects $(60 \%)$, was yun zhi (Coriolus). Only $21 \%$ of the subjects using a Chinese supplement consulted a Chinese medical practitioner before taking the supplement. Of the 14 subjects (17\%) who took Western medicinal supplements, 12 (86\%) took vitamins. Of the 12 subjects ( $15 \%$ ) who took supplements "extracted from other plants or animals", four (33\%) took shark extract.

The subjects' knowledge of these various DS came from a number of sources. Most (60\%) learned about them from friends or family members, while $21 \%$ were told about them by a Chinese medical practitioner and 19\% learned about them through the media or from seminars. Table 5 shows that expenditure on DS by breast cancer subjects was US $\$ 257.8 \pm 2.6$ per month. On average, they spent US\$2.6 \pm 9.5 on Western DS, US\$250 \pm 257.8 on Chinese DS, and US\$5.2 \pm 17.7 on other types of DS.

Table 2 Demographic characteristics of dietary supplement used by breast cancer patients

\begin{tabular}{|c|c|c|c|c|}
\hline & \multirow{2}{*}{\multicolumn{2}{|c|}{ Category }} & \multicolumn{2}{|c|}{ Use of supplement } \\
\hline & & & $\begin{array}{l}\text { Yes } \\
(n=8 I)\end{array}$ & $\begin{array}{l}\text { No } \\
(n=I)\end{array}$ \\
\hline Age (years) & \multicolumn{2}{|l|}{ Mean (SD) } & $45.9(6.9)$ & 39 (n.a.) \\
\hline $\begin{array}{l}\text { Duration in } \\
\text { Hong Kong } \\
\text { (years) }\end{array}$ & \multicolumn{2}{|l|}{ Mean (SD) } & $35.7(15.3)$ & 21 (n.a.) \\
\hline \multicolumn{5}{|c|}{ Interval from cancer diagnosis to survey (weeks) } \\
\hline & \multicolumn{2}{|c|}{ Mean (SD) } & $56.6(28.2)$ & 20 (n.a.) \\
\hline \multirow[t]{2}{*}{ Education } & \multicolumn{2}{|l|}{$\leq$ Primary level } & $36(100 \%)$ & $0(0 \%)$ \\
\hline & \multicolumn{2}{|l|}{$\geq$ Secondary level } & $45(97.8)$ & I $(2.2 \%)$ \\
\hline \multirow[t]{2}{*}{ Occupation } & \multicolumn{2}{|l|}{ Working class } & $27(96.4 \%)$ & I (3.6\%) \\
\hline & \multicolumn{2}{|l|}{$\begin{array}{l}\text { Housewife/ } \\
\text { retired/ } \\
\text { unemployed }\end{array}$} & $54(100 \%)$ & $0(0 \%)$ \\
\hline \multirow[t]{2}{*}{ Religion } & \multicolumn{2}{|l|}{ belief } & $33(100 \%)$ & $0(0 \%)$ \\
\hline & \multicolumn{2}{|l|}{ Have religious } & $48(98 \%)$ & I (2\%) \\
\hline Marital & & $8(100 \%)$ & $0(0 \%)$ \\
\hline status & \multicolumn{2}{|l|}{ Married } & $73(98.6 \%)$ & $\mathrm{I}(\mathrm{I} .4 \%)$ \\
\hline Location & \multicolumn{2}{|l|}{ Hong Kong } & 48 (100\%) & $0(0 \%)$ \\
\hline of birth & \multicolumn{2}{|l|}{ Other countries } & 33 (97.I\%) & I (2.9\%) \\
\hline Location of & \multicolumn{2}{|l|}{ Not New } & 31 (96.9\%) & I (3.1\%) \\
\hline residence & \multicolumn{2}{|l|}{ Territories } & & \\
\hline & \multicolumn{2}{|l|}{ New Territories } & $50(100 \%)$ & $0(0 \%)$ \\
\hline \multirow[t]{3}{*}{ Cancer status } & \multicolumn{2}{|l|}{ Stage I } & 23 (95.8\%) & I $(4.2 \%)$ \\
\hline & \multicolumn{2}{|l|}{ Stage II } & $5 \mathrm{I}(100 \%)$ & $0(0 \%)$ \\
\hline & \multicolumn{2}{|l|}{ Stage III } & $7(100 \%)$ & $0(0 \%)$ \\
\hline \multirow{8}{*}{$\begin{array}{l}\text { Cancer } \\
\text { treatment }\end{array}$} & \multirow[t]{2}{*}{ Surgery } & Yes & $8 \mathrm{I}(98.8 \%)$ & I (1.2\%) \\
\hline & & No & $0(0 \%)$ & $0(0 \%)$ \\
\hline & \multirow[t]{2}{*}{ Chemotherapy } & Yes & 63 (98.4\%) & I (I.6\%) \\
\hline & & No & $18(100 \%)$ & $0(0 \%)$ \\
\hline & \multirow[t]{2}{*}{ Radiotherapy } & Yes & $6 \mathrm{I}(100 \%)$ & $0(0 \%)$ \\
\hline & & No & 20 (95.2\%) & I (4.8\%) \\
\hline & Hormone & Yes & $58(100 \%)$ & $0(0 \%)$ \\
\hline & $\begin{array}{l}\text { replacement } \\
\text { therapy }\end{array}$ & No & 23 (95.8\%) & I (4.2\%) \\
\hline
\end{tabular}

Abbreviations: SD, standard deviation; n.a, not available. 
Table 3 Classification and frequency of dietary supplement used in 82 breast cancer patients

\begin{tabular}{ll}
\hline & Frequency (\%) \\
\hline Dietary supplement & \\
No & $\mathrm{I}(1.2 \%)$ \\
Yes & $8 \mathrm{I}(98.8)$ \\
Western supplement & $14(17.3 \%)$ \\
Chinese supplement & $8 \mathrm{I}(100 \%)$ \\
Herbal tea & $53(65.4 \%)$ \\
Herbal soup & $48(59.3 \%)$ \\
Proprietary medicine & $42(51.9 \%)$ \\
Other plant/animal supplements & $12(14.8 \%)$ \\
\hline
\end{tabular}

\section{Reasons for and expectations of DS use}

In Table 6 , the main reasons given by the 81 breast cancer patients who used DS as an adjuvant to conventional cancer treatment were that these supplements would "enhance recovery from cancer" (47\%), "prevent cancer recurrence" (31\%), or "boost the immune system" (26\%). Others expected that the DS would lessen the side effects associated with chemotherapy (14\%) and hormone replacement therapy (5\%).

Seven $(9 \%)$ of the 81 breast cancer subjects who took DS experienced adverse events which might have been related to these supplements, including diarrhea $(\mathrm{n}=3)$, itchy skin $(n=2)$, and stomach discomfort $(n=2)$. None of the subjects who experienced such adverse events consulted either a Chinese medical practitioner or a physician or nurse. They merely stopped taking the DS until the symptoms disappeared.

\section{Reasons for disclosure of DS use to clinicians}

Only three (4\%) of the 81 subjects who took DS said that they had been asked by an oncologist or a nurse whether they were taking DS, and the single subject who did not take DS was not asked either. Sixty of the 81 subjects (74\%) did not inform their oncologists that they were using DS during follow-up. Most of them (95\%) said that the reason they did not confide in their doctors or nurses was they believed that doctors and nurses did not care about DS, did not ask them whether they used them, did not approve of DS, and/or did not know much about them. Two subjects (3\%) believed that DS counted as food, and could therefore be taken safely and without any prejudice to the conventional cancer treatment they were receiving. Twenty-one subjects $(26 \%)$ consulted Chinese medical practitioners, instead of their oncologist or nurse, because they believed that Chinese medicine could provide holistic care.
Table 4 Top five dietary supplement ingredients used in 81 breast cancer patients

\begin{tabular}{|c|c|c|}
\hline $\begin{array}{l}\text { Type of dietary supplement } \\
\text { and ingredients }\end{array}$ & Frequency & Percent \\
\hline \multicolumn{3}{|l|}{$\begin{array}{l}\text { Western supplement } \\
\text { ingredients (14 users)* }\end{array}$} \\
\hline Any vitamins & 12 & 86 \\
\hline Calcium supplement & 6 & 43 \\
\hline Glucosine sulphate & I & 7 \\
\hline Omega3 & 1 & 7 \\
\hline \multicolumn{3}{|l|}{ Herbal tea ingredients } \\
\hline \multicolumn{3}{|l|}{ (53 users) } \\
\hline Hedyotis diffusa & 29 & 55 \\
\hline Herba scutellariae barbatae & 24 & 45 \\
\hline Ganoderma lucidum & 14 & 26 \\
\hline Spica prunellae & 8 & 15 \\
\hline Flos lonicerae japonicae and & 7 & 13 \\
\hline \multicolumn{3}{|l|}{ Flos chrysanthemi } \\
\hline \multicolumn{3}{|l|}{ Herbal soup ingredients } \\
\hline \multicolumn{3}{|l|}{ (48 users) } \\
\hline Rhizoma dioscoreae & 29 & 60 \\
\hline Semen euryales & 20 & 42 \\
\hline Fructus lycii & 16 & 33 \\
\hline Arillus longan & 12 & 25 \\
\hline Semen nelumbinis & 11 & 23 \\
\hline \multicolumn{3}{|l|}{ Chinese proprietary medicine } \\
\hline \multicolumn{3}{|l|}{ (42 users) } \\
\hline Coriolus vesicolor & 25 & 60 \\
\hline Ganoderma lucidum & 16 & 38 \\
\hline Radix isatidis & 1 & 2 \\
\hline Radix et Rhizoma ginseng & I & 2 \\
\hline Pteria margaritifera & 1 & 2 \\
\hline \multicolumn{3}{|c|}{$\begin{array}{l}\text { Other plants/animals extraction } \\
\text { supplements ( } 12 \text { users) }\end{array}$} \\
\hline Shark extraction & 4 & 33 \\
\hline Fish oil extraction & 3 & 25 \\
\hline Bird nest extraction & I & 8 \\
\hline Green tea extraction & I & 8 \\
\hline Grape seed extraction & I & 8 \\
\hline
\end{tabular}

Note: *Only 4 types of western supplements reported in $8 \mathrm{I}$ breast cancer patients.

Twenty-one subjects (26\%) disclosed to their oncologist during conventional cancer management that they were using DS, because they believed that the physicians should have complete knowledge of their CAM practice to avoid any possibility of adverse drug interaction.

\section{Concerns about using DS}

Sixty-six breast cancer patients (81\%) wanted stricter government regulation of Chinese proprietary medicine. Their concerns included clinical trial safety (89\%), possible side effects $(84 \%)$, clinical trial efficacy $(76 \%)$, exact and complete herbal constituent lists (79\%), stringent DS licensing (62\%), and authentication of the herbs (24\%). Forty-six patients $(56 \%)$ said that the government should make information on DS readily available to consumers through some sort of public enquiry system. 
Table 5 Expenditure on dietary supplement per month (US\$) in 82 breast cancer patients

\begin{tabular}{lll}
\hline & Mean (SD) & Median (range) \\
\hline Dietary supplement & $257.8(2.6)$ & $178.8(0-1679.9)$ \\
Western supplement & $2.6(9.5)$ & $0(0-59.8)$ \\
Chinese supplement & $250(257.8)$ & $178.8(0-1679.9)$ \\
$\quad$ Herbal tea & $14.7(48.7)$ & $0.8(0-412.8)$ \\
Herbal soup & $29.7(100.4)$ & $1.3(0-717.9)$ \\
$\quad$ Proprietary medicine & $67.5(140.4)$ & $3.2(0-112.5)$ \\
$\quad$ Traditional Chinese medicine & $138.1(166.8)$ & $76.9(0-717.9)$ \\
$\quad$ practitioner consultation & & \\
Other plants/animals supplements & $5.2(17.7)$ & $0(0-92.3)$ \\
\hline
\end{tabular}

\section{Discussion}

A number of studies have reported that better educated female breast cancer patients are more likely to use DS., ${ }^{8,14,25}$ The relationship between age and DS use is inconsistent. Studies by Boon et al and Velicer and Ulrich have reported that older women (ie, women aged 40-64 years) are more likely to use DS. ${ }^{14,18}$ Other studies, however, suggest precisely the opposite..$^{5,14,25,26}$ Some studies have also suggested that patients receiving chemotherapy, either because their cancer was more advanced or because they were under greater stress, were more likely to use DS to relieve stress. ${ }^{7,12,25,27}$ Demographic and clinical conditions were not significantly different between DS users and the single nonuser in this study. It might be argued that this sample is likely to overestimate the use of DS because its participants are more likely to be individuals inclined to use DS and the use of convenience sampling. In line with a number of previous studies, we found no association between DS use and marital status, religious beliefs, and length of residence in Hong Kong. ${ }^{8,20,25}$

In this pilot survey of 82 female breast cancer outpatients at Hong Kong cancer centers, it was found that the use of DS

Table 6 Reason for taking dietary supplements in 81 breast cancer patients

\begin{tabular}{ll}
\hline Reasons & Frequency (\%) \\
\hline Enhance recovery & $38(47 \%)$ \\
Cancer prevention & $25(31 \%)$ \\
Enhance immune & $21(26 \%)$ \\
Lessen side effects of chemotherapy & $11(14 \%)$ \\
Lessen side effects of hormone replacement & $4(5 \%)$ \\
therapy & \\
Clear disease root & $3(4 \%)$ \\
Remove internal heat and toxin & $3(4 \%)$ \\
General health promotion & $3(4 \%)$ \\
Increase survival rate & $1(1 \%)$ \\
\hline
\end{tabular}

by patients as an adjuvant to conventional cancer treatment was almost universal. This extraordinarily high level of use is comparable with that reported in Shanghai $(85 \%)$, but considerably higher than most usage rates reported in the US and Western Europe (28\%-83\%). The high usage rate in Hong Kong probably reflects the esteem traditionally accorded to herbal remedies in Chinese culture..$^{4,12,13,28}$ However, less than a quarter of patients would disclose their usage of DS. It was found that almost all breast cancer patients continually used DS once their cancer had been diagnosed, and the majority of them used at least one DS. Herbs were the most popular type of DS, followed by vitamins and shark extract. This pattern accords with those reported in the studies by Gotay and Dumitriu in the US and Cui et al in Shanghai. ${ }^{28-30}$ The average monthly expenditure of US\$258 on DS seems very high, but there are little data available for comparison. It was conservatively estimated that expenditure on DS in the US in 2004 was US $\$ 14.9$ billion, ${ }^{31}$ but given the cultural differences between Americans and Hong Kong Chinese, their different interpretations of what might count as a DS, and the different sampling method, this figure cannot be usefully compared.

Consistent with the findings of studies by Owens, Sollner et al, and Sparber et al, patients used DS because they were anxious to do everything possible to enhance their recovery from cancer treatment, to try to prevent a recurrence of cancer, and to try to boost their immune system. ${ }^{7,8,32}$

Effective communication between patients and their health care providers is critical in exploring CAM's role in cancer treatment. ${ }^{33}$ For many years, the utilization pattern of CAM in cancer patients was unclear, largely because physicians never asked their patients whether they were using CAM..$^{34}$ In this study, for example, only few patients reported that their oncologists had asked them whether they were using DS. Fortunately, other evidence suggests that, in certain cases, patients are likely to discuss the use of CAM with their physicians. Two studies predating the present study by one or two years indicate that almost one half of cancer survivors discussed CAM with either their physicians or nurses. ${ }^{18,35}$ Although the evidence from these studies is mixed, health professionals clearly need to take the initiative in discussing DS use with their patients. In this study, it was found that less than one-third of the participants informed their physicians or nurses that they were using DS, and they did so during follow-up rather than at the beginning of their cancer treatment. Most patients said that the reason they did not confide in their doctors or nurses was that they believed that Western medical doctors and nurses did not care about DS, did not 
ask them whether they used them, did not approve of DS, and/or did not know much about them.

Although most participants in this study reported no serious ill effects from using DS, a few patients experienced suspected adverse events, including mild diarrhea, itchy skin, and stomach discomfort, which was believed to be related to the known adverse effects of chemotherapy, radiation, surgical side effects, and hormone therapy, consistent with the findings of other studies. ${ }^{36,37}$ Most participants believed that DS were a kind of food and, therefore, saw no need to inform health professionals that they were using them or about any possible adverse events. Interestingly, they were not so much concerned that DS might interact adversely with Western medicine as they were about the effectiveness and safety of DS per se. They wanted to know precisely what herbs were used, and what measures were taken to ensure quality control. There was great interest in obtaining more information on DS. Surprisingly, most of the patients who used Chinese supplements were told about them by friends or family members. Relatively few patients got their information by consulting a Chinese medical practitioner. This finding is in line with the observation in Henderson and Donatelle's study that most women with breast cancer used at least one CAM therapy without the recommendation of their doctor. ${ }^{5}$ Clearly, it would be preferable if patients had access to full and accurate information on DS, and this is an area where public health authorities, individual physicians, and Chinese medical practitioners all have a role to play.

Our study had several limitations. First, due to its small sample size, it may not have distinguished between the characteristics of DS users and nonusers. A study with a larger sample size should be considered in order to increase the generalizability of the findings. Second, information on the perceived benefits of using DS was not collected. Thus, future qualitative and quantitative studies should consider investigating the possible benefits reported by DS users, and attempt to obtain further information on the effects of DS on conventional cancer therapy and cancer recurrence and survival rates. Last, but not least, the study employed self-reported data, which may inaccurately reflect actual adverse effects from DS. Despite these limitations, the study findings are based on a sample from multiple institutions with a high response rate, and thus provide useful information about perceived concerns resulting from the use of DS by cancer patients.

\section{Conclusion}

To our knowledge, this is the first survey to be conducted on DS use and attitudes towards it among female breast cancer patients in Hong Kong. The almost universal use of DS indicates a higher than expected level of interest in such supplements, and a widespread willingness to use them. Three-quarters of the 81 patients who took DS said that they would like detailed and reliable information on DS, but most of them felt that they could not discuss this topic with their physicians and nurses during oncology follow-up. They preferred a nonjudgmental source of information, such as a government hotline. Therefore, open communication by health professionals, regulation of labeling of DS, and patient education about use of DS are required.

\section{Acknowledgment}

We thank Dr MCM Chan, Dr BKB Law, Dr WMM Yeo, and Dr PSY Cheung for the recruitment of cancer patients for this study.

\section{Disclosure}

The authors have no financial support or relationships that may pose a conflict of interest in this work.

\section{References}

1. Parkin DM, Bray F, Ferlay J, Pisani P. Global cancer statistics, 2002. CA Cancer J Clin. 2005;55:74-108.

2. Patrick DL, Ferketich SL, Frame PS, et al. National Institutes of Health State-of-the-Science Conference Statement: Symptom management in cancer: pain, depression, and fatigue, 2002 Jul 15-17. J Natl Cancer Inst. 2003;95:1110-1117.

3. Eustachi A. Complementary therapies in breast cancer patients. Breast Care. 2007;2:209-216.

4. Burstein HJ, Gelber S, Guadagnoli E, Weeks JC. Use of alternative medicine by women with early-stage breast cancer. $N$ Engl J Med. 1999;340:1733-1739.

5. Henderson JW, Donatelle RJ. Complementary and alternative medicine use by women after completion of allopathic treatment for breast cancer. Altern Ther Health Med. 2004;10:52-57.

6. Lengacher CA, Bennett MP, Kipp KE, Berarducci A, Cox CE. Design and testing of the use of a complementary and alternative therapies survey in women with breast cancer. Oncol Nurs Forum. 2003;30: 811-821.

7. Owens B. A test of the self-help model and use of complementary and alternative medicine among Hispanic women during treatment for breast cancer. Oncol Nurs Forum. 2007;34:E42-E50.

8. Sparber A, Bauer L, Curt G, et al. Use of complementary medicine by adult patients participating in cancer clinical trials. Oncol Nurs Forum. 2000;27:623-630.

9. Harris P, Rees R. The prevalence of complementary and alternative medicine use among the general population: A systematic review of the literature. Complement Ther Med. 2000;8:88-96.

10. Thomas K, Coleman P. Use of complementary or alternative medicine in a general population in Great Britain. Results from the National Omnibus survey. J Public Health (Oxf). 2004;26:152-157.

11. Lim MK, Sadarangani P, Chan HL, Heng JY. Complementary and alternative medicine use in multiracial Singapore. Complement Ther Med. 2005;13:16-24.

12. diGianni LM, Garber JE, Winer EP. Complementary and alternative medicine use among women with breast cancer. J Clin Oncol. 2002;20:S34-S38. 
13. Rees RW, Feigel I, Vickers A, Zollman C, McGurk R, Smith C. Prevalence of complementary therapy use by women with breast cancer. A population-based survey. Eur J Cancer. 2000;36:1359-1364.

14. Velicer CM, Ulrich CM. Vitamin and mineral supplement use among US adults after cancer diagnosis: A systematic review. J Clin Oncol. 2008;26:665-673.

15. American Health Association. More hospitals offering CAM services. 2008. Available from: http://www.aha.org/aha/press release/2008/080915-pr-cam.html. Accessed 2010 Sep 30.

16. Richardson MA, Sanders T, Palmer JL, Greisinger A, Singletary SE. Complementary/alternative medicine use in a comprehensive cancer center and the implications for oncology. J Clin Oncol. 2000;18:2505-2514.

17. Trager-Maury S, Tournigand C, Maindrault-Goebel F, et al. Use of complementary medicine by cancer patients in a French oncology department. Bull Cancer. 2007;94:1017-1025.

18. Boon H, Stewart M, Kennard MA, et al. Use of complementary/ alternative medicine by breast cancer survivors in Ontario: Prevalence and perceptions. J Clin Oncol. 2000;18:2515-2521.

19. Ganz PA, Desmond KA, Leedham B, Rowland JH, Meyerowitz BE, Belin TR. Quality of life in long-term, disease-free survivors of breast cancer: A follow-up study. J Natl Cancer Inst. 2002;94:39-49.

20. Lengacher CA, Bennett MP, Kip KE, et al. Frequency of use of complementary and alternative medicine in women with breast cancer. Oncol Nurs Forum. 2002;29:1445-1452.

21. US Food and Drug Administration. Overview of dietary supplements. 2001.Available from: http://www.fda.gov/food/dietarysupplments/ consumerinformation/ucm 110417.htm. Accessed 2010 Oct 27.

22. Cassileth BR, Vickers AJ. High prevalence of complementary and alternative medicine use among cancer patients: Implications for research and clinical care. J Clin Oncol. 2005;23:2590-2592.

23. Appadurai IR, Hanna CL. Concerns with complementary and alternative medicines. Eur J Anaesthesiol. 2006;23:441-442.

24. Singletary SE, Allred C, Ashley P, et al. Revision of the American Joint Committee on Cancer staging system for breast cancer. J Clin Oncol. 2002;20:3628-3636.

25. Boon HS, Olatunde F, Zick SM. Trends in complementary/alternative medicine use by breast cancer survivors: Comparing survey data from 1998 and 2005. BMC Womens Health. 2007;7:4.
26. Matthews AK, Sellergren SA, Huo D, List M, Fleming G. Complementary and alternative medicine use among breast cancer survivors. J Altern Complement Med. 2007;13:555-562.

27. Redd WH, Montgomery GH, du Hamel KN. Behavioral intervention for cancer treatment side effects. J Natl Cancer Inst. 2001;93: $810-823$.

28. Cui Y, Shu XO, Gao Y, et al. Use of complementary and alternative medicine by Chinese women with breast cancer. Breast Cancer Res Treat. 2004;85:263-270.

29. Fouladbakhsh JM, Stommel M, Given BA, Given CW. Predictors of use of complementary and alternative therapies among patients with cancer. Oncol Nurs Forum. 2005;32:1115-1122.

30. Gotay CC, Dumitriu D. Health food store recommendations for breast cancer patients. Arch Fam Med. 2000;9:692-699.

31. Eisenberg DM, Davis RB, Ettner SL, et al. Trends in alternative medicine use in the United States, 1990-1997: Results of a follow-up national survey. JAMA. 1998;280:1569-1575.

32. Sollner W, Maislinger S, DeVries A, Steixner E, Rumpold G, Lukas P. Use of complementary and alternative medicine by cancer patients is not associated with perceived distress or poor compliance with standard treatment but with active coping behavior: A survey. Cancer. 2000;89:873-880

33. Adler SR, Fosket FR. Disclosing complementary and alternative medicine use in the medical encounter: A qualitative study in women with breast cancer. J Fam Pract. 1999;48:453-458.

34. Penson RT, Castro CM, Seiden MV, Chabner BA, Lynch TJ. Complementary, alternative, integrative, or unconventional medicine? Oncologist. 2001;6:463-473.

35. Balneaves LG, Kristjanson LJ, Tataryn D. Beyond convention: Describing complementary therapy use by women living with breast cancer. Patient Educ Couns. 1999;38:143-153.

36. Shih V, Chiang JY, Chan A. Complementary and alternative medicine (CAM) usage in Singaporean adult cancer patients. Ann Oncol. 2009;20:752-757.

37. Goldstein MS, Lee JH, Ballard-Barbash R, Brown ER. The use and perceived benefit of complementary and alternative medicine among Californians with cancer. Psychooncology. 2008;17:19-25.
Patient Preference and Adherence

\section{Publish your work in this journal}

Patient Preference and Adherence is an international, peer-reviewed, open access journal focusing on the growing importance of patient preference and adherence throughout the therapeutic continuum. Patient satisfaction, acceptability, quality of life, compliance, persistence and their role in developing new therapeutic modalities and compounds to

\section{Dovepress}

optimize clinical outcomes for existing disease states are major areas of interest. This journal has been accepted for indexing on PubMed Central. The manuscript management system is completely online and includes a very quick and fair peer-review system. Visit http://www.dovepress.com/ testimonials.php to read real quotes from published authors. 